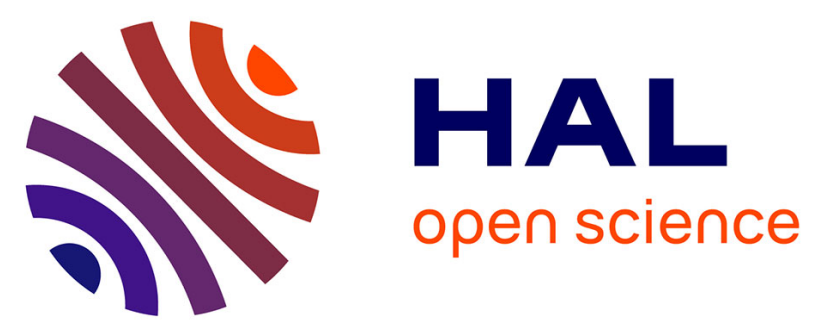

\title{
Enantiopure vs. Racemic Naphthalimide End-Capped Helicenic Non-Fullerene Electron Acceptors: Impact on Organic Photovoltaics Performance
}

\author{
Pierre Josse, Ludovic Favereau, Chengshuo Shen, Sylvie Dabos-Seignon, \\ Philippe Blanchard, Clement Cabanetos, Jeanne Crassous
}

\section{To cite this version:}

Pierre Josse, Ludovic Favereau, Chengshuo Shen, Sylvie Dabos-Seignon, Philippe Blanchard, et al.. Enantiopure vs. Racemic Naphthalimide End-Capped Helicenic Non-Fullerene Electron Acceptors: Impact on Organic Photovoltaics Performance. Chemistry - A European Journal, 2017, 23 (26), pp.6277-6281. 10.1002/chem.201701066 . hal-01497181

HAL Id: hal-01497181

https://hal-univ-rennes1.archives-ouvertes.fr/hal-01497181

Submitted on 28 Mar 2017

HAL is a multi-disciplinary open access archive for the deposit and dissemination of scientific research documents, whether they are published or not. The documents may come from teaching and research institutions in France or abroad, or from public or private research centers.
L'archive ouverte pluridisciplinaire HAL, est destinée au dépôt et à la diffusion de documents scientifiques de niveau recherche, publiés ou non, émanant des établissements d'enseignement et de recherche français ou étrangers, des laboratoires publics ou privés. 


\title{
Enantiopure vs. Racemic Naphthalimide End-Capped Helicenic Non-Fullerene Electron Acceptors: Impact on Organic Photovoltaics Performance
}

\author{
Pierre Josse, ${ }^{\mathrm{a}}$ Ludovic Favereau, ${ }^{\mathrm{b}}{ }^{*}$ Chengshuo Shen, ${ }^{\mathrm{b}}$ Sylvie Dabos-Seignon, ${ }^{\mathrm{a}}$ Philippe Blanchard, ${ }^{\mathrm{a} *}$ \\ Clément Cabanetos, ${ }^{a *}$ and Jeanne Crassous ${ }^{\mathrm{b} *}$
}

\begin{abstract}
Impact of the enantiopurity on organic photovoltaics (OPV) performance was investigated through the synthesis of racemic and enantiomerically pure naphthalimide end-capped helicenes and their application as non-fullerene molecular electron acceptors in OPV devices. A very strong increase of the device performance was observed by simply switching from the racemic to the enantiopure forms of these $\pi$-helical non-fullerene acceptors with power conversion efficiencies jumping from $0.4 \%$ to $\mathrm{ca} 2.0 \%$ in airprocessed poly(3-hexylthiophene) based devices, thus highlighting the key role of enantiopurity in the photovoltaic properties.
\end{abstract}

Chiral molecular materials have recently attracted considerable attention in optoelectronic domains, especially due to their specific interaction with circularly polarized light. ${ }^{[1]}$ Another fundamental aspect in chirality is that the chemical and physical properties of the two enantiomers of a chiral molecule and of its corresponding racemate are identical in solution but may be different in the solid state due to different packing and for symmetry reasons. ${ }^{[2]}$ However surprisingly this aspect has not triggered major interest for the design of novel $\pi$-conjugated materials for organic photovoltaics (OPV) despite the well-known strong impact of the solid state packing on the films properties. ${ }^{[3]}$ Indeed, few reports have addressed the influence of chirality of $\pi$-conjugated systems on the overall device performance, focusing almost exclusively on chiral alkyl side-chain engineering. ${ }^{[4]}$ For instance, Nguyen then Castellano published diketopyrrolopyrrole-based molecular electron-donors functionalized either by racemic or enantiomeric pure 2ethylhexyl side chains in OPV devices (Scheme 1a), ${ }^{[5]}$ and concluded that stereoisomerism had a minor impact on devices performances. A contrario, Itoh recently reported detrimental effects on power conversion efficiencies (PCE) when using $\left[\mathrm{C}_{60}\right]-$ fullerene derivatives as molecular electron-acceptors functionalized by optically active cyclohexene and menthyl ester groups. ${ }^{[6]}$ However, these studies only explored diastereomeric relationships, and surprisingly no systems with enantiomeric relationship has been examined so far in OPV devices (Scheme 1a).

Herein, the impact of enantiopurity on the photovoltaic performance is addressed by using chiral fully $\pi$-conjugated materials either in their racemic or enantiopure forms. As a proof of concept, we report the first implement of chiral [6]helicene

[a] P. Josse, S. Dabos-Seignon, P. Blanchard, C. Cabanetos, CNRS UMR 6200, MOLTECH-Anjou, University of Angers, 2 Bd Lavoisier, 49045 Angers, France. E-mail: philippe.blanchard@univ-angers.fr; clement.cabanetos@univ-angers.fr

[b] C. Shen, Dr. L. Favereau, Dr. J. Crassous, Institut des Sciences Chimiques de Rennes UMR 6226, Institut de Physique de Rennes, UMR 6251, CNRS Université de Rennes 1, Campus de Beaulieu, 35042 Rennes Cedex (France). E-mail: ludovic.favereau@univrennes1.fr; jeanne.crassous@univ-rennes1.fr

Supporting information for this article is given via a link at the end of the document. derivatives as non-fullerene acceptors (NFAs). Indeed, helicenes have received little attention as molecular materials in OPV, ${ }^{[7]}$ despite $i$ ) their unique intrinsically chiral 3-dimensional helical $\pi$ conjugated skeleton that provides strong chiroptical properties, ${ }^{[8]}$ and ii) their good charge transport properties. ${ }^{[7 a, 9]}$ In addition, the development of NFAs has recently generated a craze in the PV community knocking down one major drawback of the fullerene derivatives which is the limited structural tunability of their energy levels. ${ }^{[10]}$

Following a strategy previously reported by our groups, we designed $\pi$-helical NFAs (racemic, rac-2 and enantiopure $P-2$ and $M-2$ ) by simply connecting two naphthtalimide groups, used as electron-transporting/withdrawing blocks, to a carbo[6] helicene unit via acetylenic linkages (Scheme 1). ${ }^{[1]}$ The photovoltaic performances of the prepared helicenic derivatives have been examined in air-processed poly(3-hexylthiophene) (P3HT)-based devices, with particular attention to the different behavior between the racemic and enantiopure systems, through the study of the photophysical, chiroptical, transport properties and surface characterizations of pure rac-2, $P-2$ and M-2, and blends with P3HT.

a) Previous works: Asymmetric carbon on side-chains
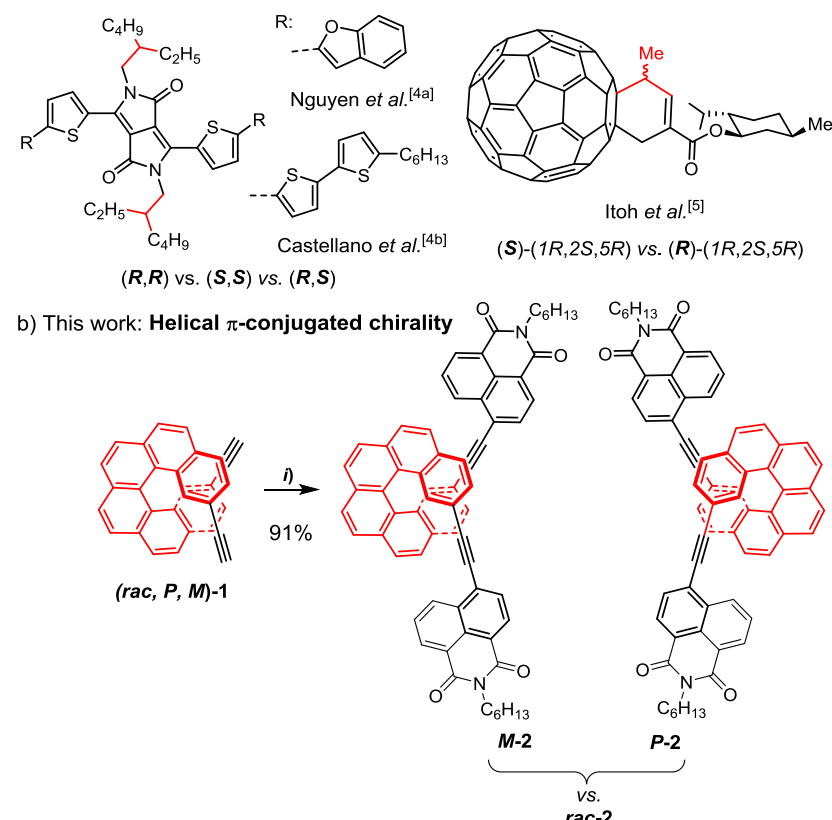

Scheme 1. Synthesis of naphthalimide end-capped helicene compounds rac$P$ - and $M$-2. i) 6-bromo-2-hexyl-1 $H$-benzoisoquinoline-1,3(2H)-dione, $\mathrm{Pd}\left(\mathrm{PPh}_{3}\right)_{4}, \mathrm{Cul}, \mathrm{Et}_{3} \mathrm{~N}$, toluene.

2,15-bisethynyl[6]helicene (1) as either rac-1, $P-\mathbf{1}$ or $M-\mathbf{1}$ was engaged in a Sonogashira cross-coupling reaction, with an excess of 6-bromo-2-hexyl-1 $H$-benzoisoquinoline-1,3(2H)-dione, affording respectively rac-, $P$ - and $M$-naphthalimide end-capped helicene derivatives (rac-2, $P-2$ and $M-2$ ) as bright yellow solids in excellent yields (see Supporting Information, SI). This simple 
synthetic strategy ensures a strong electronic interaction between the chiral $\pi$-conjugated backbone and the electronaccepting naphthalimide units (vide infra.).

As expected, rac-2, $P-2$ and $M-2$ show similar UV-Vis absorption spectra in $\mathrm{CH}_{2} \mathrm{Cl}_{2}$ solutions, characterized by three main absorption bands at ca 300,360 , and $420 \mathrm{~nm}$ respectively, associated with high extinction coefficients $(\varepsilon)$ of $7.0 \times 10^{4}, 5.8 \times$ $10^{4}$ and $6.0 \times 10^{4} \mathrm{M}^{-1} \mathrm{~cm}^{-1}$ (Figure 1). Moreover, a strong bathochromic shift coupled to an increase in intensity were recorded compared to the helicenic and naphthalmide precursors, evidencing an extended $\pi$-conjugation through the $\mathrm{m}$

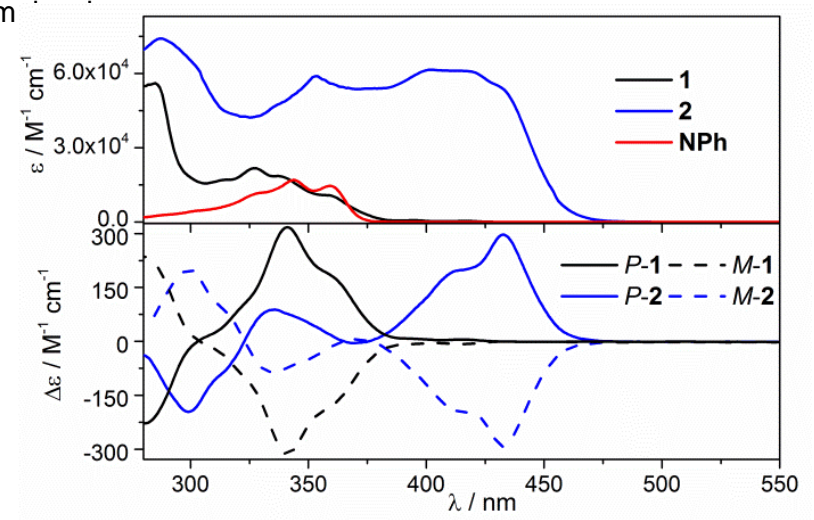

Figure 1. UV-Vis absorption spectra of precursors 1 (black) and 6-bromo-2 hexyl-1H-benzoisoquinoline-1,3(2H)-dione (NPh, red), and $\pi$-helical NFA 2 (blue, top) and ECD spectra of corresponding enantiomers $P$-(solid line) and $M$-(dashed line) in $\mathrm{CH}_{2} \mathrm{Cl}_{2}$ at $298 \mathrm{~K}$.

Electronic Circular Dichroism (ECD) measurements of $P-2$ and M-2 were performed in $\mathrm{CH}_{2} \mathrm{Cl}_{2}$, displaying expected mirrorimage relationships (Figure 1). ${ }^{[8 a]}$ Enantiomer $P$-2 exhibits a strong negative band at $300 \mathrm{~nm}\left(\Delta \varepsilon=-200 \mathrm{M}^{-1} \mathrm{~cm}^{-1}\right)$, a medium positive band at $330 \mathrm{~nm}\left(\Delta \varepsilon=+80 \mathrm{M}^{-1} \mathrm{~cm}^{-1}\right)$, and two strong positive ones at lower energy $\left(\Delta \varepsilon=+200\right.$ and $+300 \mathrm{M}^{-1} \mathrm{~cm}^{-1}$ at 410 and $430 \mathrm{~nm}$, respectively). These ECD-active bands are strongly red-shifted in comparison with the bis(ethynyl)[6]helicene 1 precursor, reflecting the significant impact of the naphthalimide units on the chiroptical properties of the whole $\pi$-conjugated helical structure. The absolute configurations $P-(+)-2$ and $M-(-)-2$ can be assigned both based on the starting helicene $\mathbf{1}$ and from the ECD results.

Rac-2, $P-2$ and $M-2$ exhibited intense luminescence in $\mathrm{CH}_{2} \mathrm{Cl}_{2}$, with an emission maximum at $510 \mathrm{~nm}$ and a measured quantum yield of $86 \%$ (Figure S8), a value which is among the highest in [6] helicene derivatives. ${ }^{[7]}$ In the solid state, the three compounds remain highly luminescent with identical spectra and maxima at $520 \mathrm{~nm}$ (Figure S9). Cyclic voltammetry enabled us to estimate identical HOMO and LUMO levels of ca $-6.4 \mathrm{eV}$ and $-3.8 \mathrm{eV}$ for rac-2, $P-2$ and $M-2$, which were respectively assigned to the oxidation of the helicene core and the reduction of the electronaccepting naphthalimide unit (See SI). ${ }^{[12]}$ An electrochemical gap of ca $2.6 \mathrm{eV}$ was thus estimated, in agreement with the absorption data.

Having these unprecedented enantiopure and racemic electron acceptors in hands, we then investigated their performance in OPV devices to probe a potential impact of enantiopurity on the photovoltaic properties. Accordingly, rac-2, $P-2$ and M-2 were blended with the archetypal and regioregular P3HT (Figure S11), a well-known scalable and relatively stable wide bandgap donor polymer, chosen for its lack of chirality on its solubilizing groups. Inverted and air-processed devices of architecture: ITO/ZnO/P3HT:rac-2, $P$-2 or $M-2(1: 2) / \mathrm{MoO}_{3} / \mathrm{Ag}$ were thus fabricated (See SI). Devices characteristics are gathered in Table 1, current density-voltage $(J-V)$ and external quantum efficiency (EQE) curves, plotted in Figure 2.

Table 1. Photovoltaic characteristics under AM. 1.5 simulated solar illumination $\left(100 \mathrm{~mW} . \mathrm{cm}^{-2}\right)$ of bulk heterojunction cells based on P3HT blended with rac-2, P-2 or M-2. ${ }^{[a]}$ Average value over 12 cells.

$\begin{array}{ccccc}\text { Acceptor } & \begin{array}{c}J_{\text {sc }} \\ \left(\mathrm{mAn}_{n} \mathrm{~cm}^{-}\right.\end{array} & V_{\text {oc }}(\mathrm{V}) & \begin{array}{c}\mathrm{FF} \\ (\%)\end{array} & \begin{array}{c}\mathrm{PCE} \\ \text { max/ave }\end{array} \\ \text { rac-2 } & 3.48 & 0.41 & 29 & 0.41 / 0.37 \\ \text { M-2 } & 6.91 & 0.62 & 49 & 2.09 / 1.89 \\ \text { P-2 } & 6.85 & 0.62 & 47 & 2.00 / 1.85\end{array}$

The photovoltaic results clearly evidenced a different behaviour using either the racemic (rac-2) or the enantiopure $\pi$ helical NFAs ( $P$ - or $M-2)$ as the electron acceptor in the active layers. Indeed, while modest PCEs of ca $0.4 \%$ were recorded for rac-2, both $\boldsymbol{P}$ - and $M-2$ based devices exhibited much stronger efficiencies of $\mathrm{ca} 2 \%$, resulting from a simultaneous increase of the open-circuit voltage $\left(V_{o c}\right)$, the short-circuit current density $\left(J_{\text {sc }}\right)$ and the fill factor $(F F)$ (Table 1 and Figure 2). In agreement with the corresponding $J_{\mathrm{sc}}$, EQE responses of the enantiopure blends $(P$ - and $M-2)$ were almost twice greater than that of rac-2 based devices, suggesting inefficient charge separation/extraction and/or morphological issues in this latter racemic case.

a)

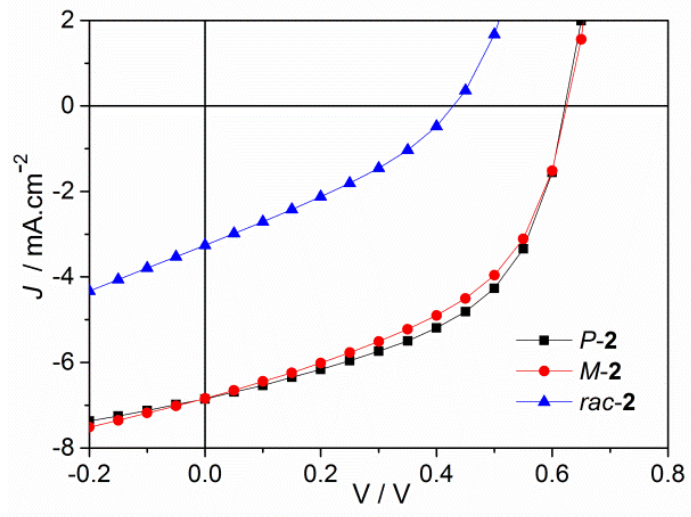

b)

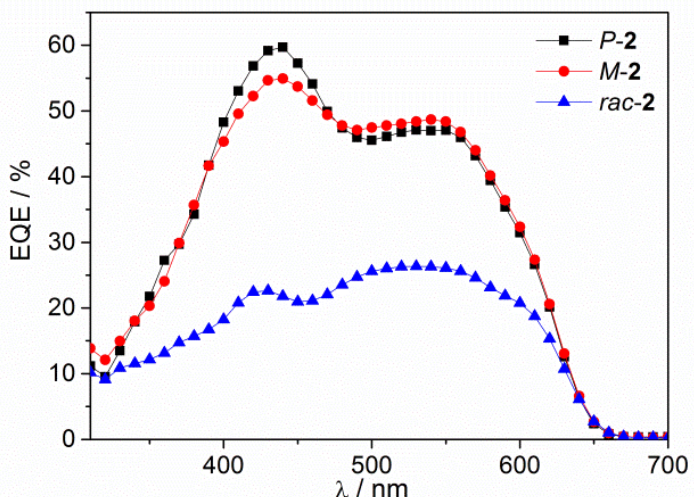

Figure 2. Current density-voltage characteristics (a) and EQE spectra (b) of inverted rac-2 (blue), P-2 (black) and $M$ - (red) 2 based OPV devices.

To the best of our knowledge, the obtained photovoltaic results highlight for the first time how enantiopurity (enantiomer vs. 
racemic compound) brought by the $\pi$-conjugated backbone may have a strong impact on the overall performance of a photovoltaic device.

The fact that enantiopure and racemic forms of a chiral compound may have different properties in the solid state, especially in terms of electronic conductivity, has already been reported for tetrathiafulvalene derivatives, dithiolene complexes and recently on azaboradibenzo-[6]helicene. ${ }^{[9 a, 13]}$ However, this work addresses another aspect, considering that the racemic and the enantiopure molecules are, in the solar cell active layer, mixed with the donor polymer $\mathbf{P} \mathbf{3 H T}$, and both contribute to the photocurrent of the cell, as evidenced by the EQE spectra (Figure 2). In this regard, the solid state assembly of pure rac-2 and P-2 (M-2) and the one with the achiral polymer electron donor within the active layer, which is a crucial point for both charges generation and migration in OSCs, must be compared to explain the significant difference observed on the photovoltaic results.

Firstly, examination of the UV-Vis spectra of spin-cast films of pure rac-2, $P-2$ or $M-2$ showed exactly similar response for the three species and no significant difference in patterns compared to the UV-Vis spectra in solution, except a $\sim 10 \mathrm{~nm}$ bathochromic shift (Figure 3). The solid state ECD spectra differ mainly from the ones in solution by both an increase and a bathochromic shift $(\sim 30 \mathrm{~nm})$ of the signal suggesting a specific intermolecular packing of the enantiomer films. Secondly, UV-Vis spectra of films obtained from active layers displayed similar patterns and relative intensities for the helicenic part compared to the films of pure rac-2, $P-2$ or $M-2$, and an additional broad and intense band between 450 and $650 \mathrm{~nm}$ attributed to the P3HT (Figure 3)

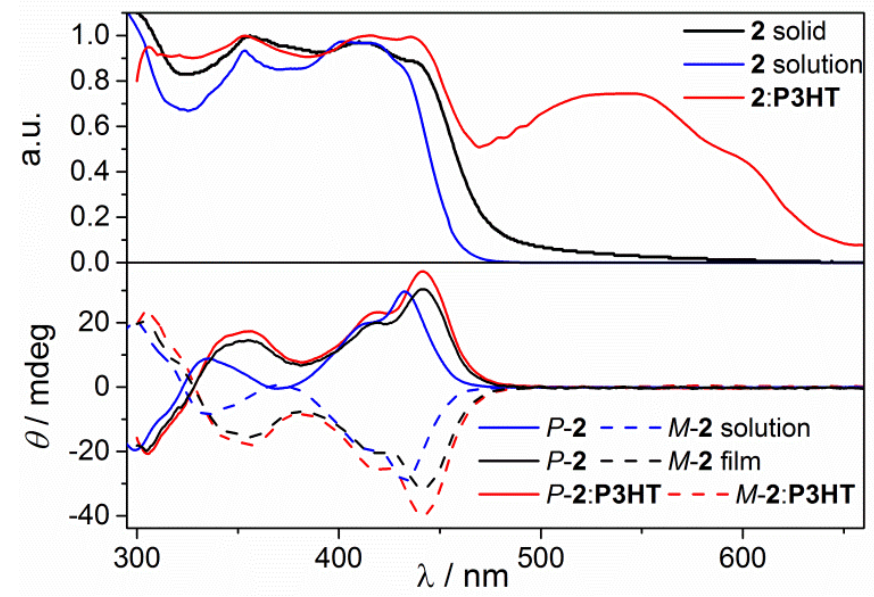

Figure 3. UV-Vis absorption spectra (top) of 2 in solution (blue), as spin-cast films (black) and blended with P3HT (red). ECD spectra (bottom) of corresponding enantiomers $P$-(solid line) and $M$-(dashed line) in solution (blue), as spin-cast films (black) and blended with P3HT (red).

The ECD spectra of $P-(M-) 2: P 3 H T$ blends exhibit the same signature as the ones of $P-(M-) 2$ films, including the intensity increase and the bathochromic shift at 350 and $450 \mathrm{~nm}$ in comparison with the solution measurement. This similarity implies that the specific homochiral packing is maintained even in the presence of the P3HT polymer. Moreover, no induced ECD signal was observed on the P3HT transitions, which precludes any chiral supramolecular organization of the achiral polymer or chiral molecular doping effect in the whole active layer (Figure 3). In other words, no induction of chirality from the helicenic molecule to the polymeric P3HT structure was observed. This system therefore behaves differently from liquid crystals doped with helicene derivatives or from polymeric structures used in chiral OLEDs that become helical in the presence of a helicenic dopant. ${ }^{[8, c, 14]}$ In addition, no difference was observed for the charge generation process, since the photoluminescence of rac- or $P-(M-) 2$ was efficiently and comparably quenched, by exciting either the electron donor at $500 \mathrm{~nm}$ or the electron acceptor at $380 \mathrm{~nm}$ of the blends (Figure S9). The above results seem to demonstrate that rac-2 and $P$ $(M-)$ 2:P3HT active layers differ only by a distinct homochiral packing of the enantiopure acceptors at the molecular level.

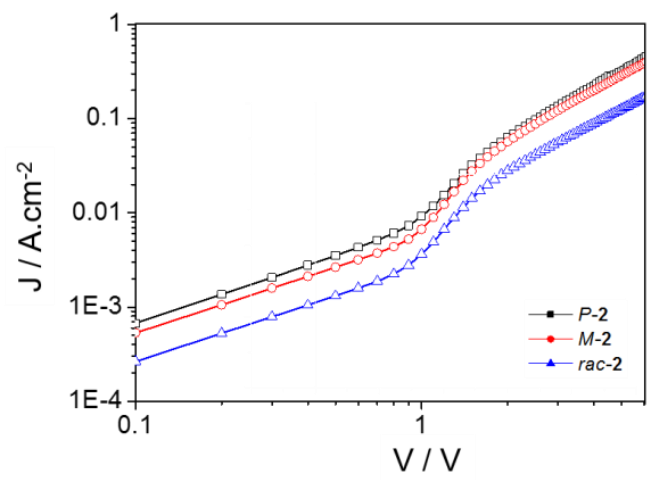

Figure 4. Electron mobility $\mu_{\mathrm{e}}$ of rac-(blue), $P$-(black) and $M$ - (red) 2 based devices.

Hence, electron mobilities $\left(\mu_{\mathrm{e}}\right)$ of the blends were evaluated using the space-charge limited current (SCLC) method (see SI). As a result, $\mu_{\mathrm{e}}$ values of ca $4.0 \times 10^{-4}$ and $1.8 \times 10^{-4} \mathrm{~cm}^{2} \mathrm{~V}^{-1} \mathrm{~s}^{-1} \mathrm{~cm}^{2}$ $\mathrm{V}^{-1} \mathrm{~s}^{-1}$ were obtained for the enantiomerically pure $(P$ - or $M-2)$ and the racemic (rac-2) active layers, respectively (Figure 4). The twofold reduction for rac-2 based OSCs probably contributes to the lower $J_{\mathrm{sc}}$ and $F F$ recorded and might be related to the specific enantiomeric interaction of $P$ - or $M-2$ within the blend as already noticed in the ECD measurements (Figure 2). Notably, the fact that $P$ - and M-2 systematically displayed comparable values ascertains the reliability of our measurements (see SI).

Further evidences of morphology difference between the racemic and the enantiopure blends were obtained by recording Atomic Force Microscopy (AFM) images of the different active layers (Figure 5). a)
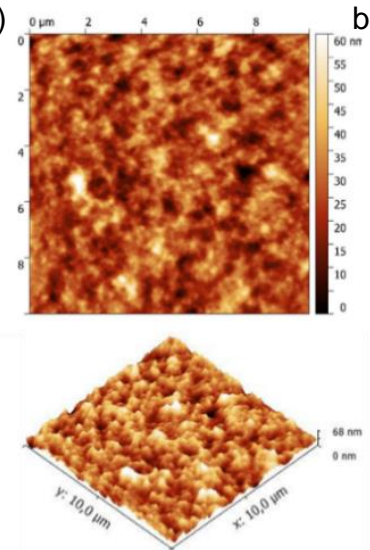

$\mathrm{RMS}=8 \mathrm{~nm}$

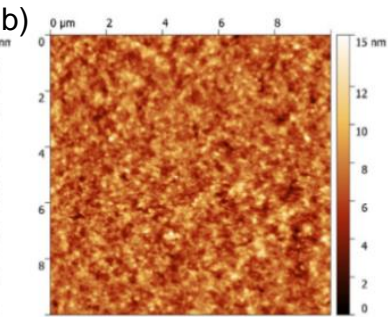

RMS $=1,5 \mathrm{~nm}$

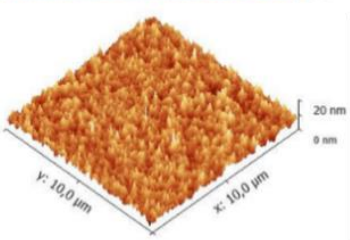

Figure 5. AFM phase images of optimized rac-2 (a) and M-2 (b) based P3HT active layers.

Indeed, the surfaces of $P$ - and M-2:P3HT blends exhibit small and homogenous domains of only tens of nanometers in size, 
while the surface of rac-2:P3HT blend shows larger coarse domains on the micrometer scale, resulting in a roughness value five times higher in the case of rac-2 $(8 \mathrm{~nm})$ than in $P$ and $M-2$ based active layers $(1.5 \mathrm{~nm})$.

In summary, we have investigated the impact of enantiopurity on the performance of photovoltaic devices by comparing racemic and enantiopure naphthalimide end-capped [6] helicenes as electron acceptors, blended with P3HT donor polymer in OSCs. In this proof of concept, a 5-fold increase of the cells efficiency was recorded going from the racemic to the enantiomerically pure electron acceptor based inverted OSCs. This significant difference was attributed to a different organization of the enantiopure compounds in the solid state, affecting both the charge transport properties and the morphology within in the active layers, resulting in better photovoltaic efficiencies. More than highlighting the potential of helicenes in OPVs, as a new class of NFAs displaying both extended $\pi$-conjugation and inherent chirality, this work also suggests that chirality may in some cases have a strong impact on the photovoltaic performance if present within the active layer of a cell.

\section{Acknowledgements}

The "Ministère de la Recherche" is acknowledged for the PhD grant of P. Josse. The PIAM (Plateforme d'Ingénierie et Analyses Moléculaires) of the University of Angers is also thanked for the characterization of organic compounds.

Keywords: helical chirality $\cdot$ organic photovoltaics $\cdot$ nonfullerene acceptors $\cdot$ enantiopurity $\bullet$ helicene

[1] a) Chirality at the Nanoscale, Nanoparticles, Surfaces, Materials and more (Ed.: D. Amabilino), Wiley-VCH, 2009, p; b) Molecular Switches (Eds: B. L. Feringa, W.R. Browne), Wiley-VCH, 2nd edition, 2011, p.

[2] A. C. J. Jacques, S. H. Wilen, Enantiomers, Racemates, \& Resolutions, J. Wiley \& Sons, New York, 1981, p. Here chemical and physical properties refer to properties characterized by unpolarized light: crystallinity, infrared spectroscopy, solubility, melting points to name a few.

[3] P. M. Beaujuge and J. M. J. Fréchet, J. Am. Chem. Soc. 2011, 133, 20009 20029

[4] Note that many studies have investigated the effect of chiral side chains on the chirality of a polymeric backbone, but to our knowledge the direct comparison of racemic vs. enantiopure has not been addressed. See for example: a) D. Kotkar, V. Joshi and P. K. Ghosh, J. Chem. Soc., Chem. Comm. 1988, 917-918; b) M. Lemaire, D. Delabouglise, R. Garreau, A. Guy and J. Roncali, J. Chem. Soc., Chem. Comm. 1988, 658-661; c) M. M. Bouman and E. W. Meijer, Adv. Mater. 1995, 7, 385-387; d) B. M. W. Langeveld-Voss, R. J. M. Waterval, R. A. J. Janssen and E. W. Meijer, Macromolecules 1999, 32, 227-230; e) E. Yashima, H. Goto and Y. Okamoto Macromolecules 1999, 32, 7942-7945; f) E. Yashima, N. Ousaka, D. Taura, K Shimomura, T. Ikai and K. Maeda, Chem. Rev. 2016; g) S. L. Fronk, M. Wang M. Ford, J. Coughlin, C.-K. Mai and G. C. Bazan, Chem. Sci. 2016, 7, 53135321.

[5] a) J. Liu, Y. Zhang, H. Phan, A. Sharenko, P. Moonsin, B. Walker, V. Promarak and T.-Q. Nguyen, Adv. Mater. 2013, 25, 3645-3650; b) R. B. Zerdan, N. T. Shewmon, Y. Zhu, J. P. Mudrick, K. J. Chesney, J. Xue and R. K. Castellano, Adv. Funct. Mater. 2014, 24, 5993-6004.

[6] K. Sugawara, N. Nakamura, Y. Yamane, S. Hayase, T. Nokami and T. Itoh, Green Energy Environ. 2016, 1, 149-155.

[7] a) S. Xiao, S. J. Kang, Y. Wu, S. Ahn, J. B. Kim, Y.-L. Loo, T. Siegrist, M. L. Steigerwald, H. Li and C. Nuckolls, Chem. Sci. 2013, 4, 2018-2023; b) G. Lewińska, K. S. Danel and J. Sanetra, Sol. Energy 2016, 135, 848-853; c) Y. Zhong, M. T. Trinh, R. Chen, G. E. Purdum, P. P. Khlyabich, M. Sezen, S. Oh H. Zhu, B. Fowler, B. Zhang, W. Wang, C.-Y. Nam, M. Y. Sfeir, C. T. Black, M L. Steigerwald, Y.-L. Loo, F. Ng, X. Y. Zhu and C. Nuckolls, Nat. Commun 2015, 6, 8242 .

[8] a) Y. Nakai, T. Mori and Y. Inoue, J. Phys. Chem. A 2012, 116, 7372-7385; b) Y. Shen and C.-F. Chen, Chem. Rev. 2012, 112, 1463-1535; c) M. Gingras, Chem. Soc. Rev. 2013, 42, 1051-1095.

[9] a) T. Hatakeyama, S. Hashimoto, T. Oba and M. Nakamura, J. Am. Chem. Soc. 2012, 134, 19600-19603; b) Y. Yang, R. C. da Costa, M. J. Fuchter and A. J. Campbell, Nat Photon 2013, 7, 634-638; c) C. Kim, T. J. Marks, A Facchetti, M. Schiavo, A. Bossi, S. Maiorana, E. Licandro, F. Todescato, S Toffanin, M. Muccini, C. Graiff and A. Tiripicchio, Org. Electron. 2009, 10, 1511-1520; d) J. Storch, J. Zadny, T. Strasak, M. Kubala, J. Sykora, M. Dusek, V. Cirkva, P. Matejka, M. Krbal and J. Vacek, Chem. Eur. J. 2015, 21, 23432347.

[10] a) A. a. F. Eftaiha, J.-P. Sun, I. G. Hill and G. C. Welch, J. Mater. Chem. A 2014, 2, 1201-1213; b) Y. Lin and X. Zhan, Mater. Horiz. 2014, 1, 470-488; c) A. D. Hendsbee, J.-P. Sun, W. K. Law, H. Yan, I. G. Hill, D. M. Spasyuk and G. C. Welch, Chem. Mater. 2016, 28, 7098-7109; d) C. Zhan and J. Yao, Chem. Mater. 2016, 28, 1948-1964; e) Y. Yang, Z.-G. Zhang, H. Bin, S. Chen, L. Gao, L. Xue, C. Yang and Y. Li, J. Am. Chem. Soc. 2016, 138, 15011-15018; f) S. Holliday, R. S. Ashraf, A. Wadsworth, D. Baran, S. A. Yousaf, C. B. Nielsen, C.-H. Tan, S. D. Dimitrov, Z. Shang, N. Gasparini, M. Alamoudi, F. Laquai, C. J. Brabec, A. Salleo, J. R. Durrant and I. McCulloch, Nat. Commun. 2016, 7 11585

[11] a) O. Vybornyi, Y. Jiang, F. Baert, D. Demeter, J. Roncali, P. Blanchard and C. Cabanetos, Dyes Pigm. 2015, 115, 17-22; b) P. Josse, C. Dalinot, Y. Jiang, S. Dabos-Seignon, J. Roncali, P. Blanchard and C. Cabanetos, J. Mater. Chem. A 2016, 4, 250-256; c) P. Josse, A. Labrunie, C. Dalinot, S. M. McAfee, S. Dabos-Seignon, J. Roncali, G. C. Welch, P. Blanchard and C. Cabanetos, Org. Electron. 2016, 37, 479-484.

[12] S. M. McAfee, J. R. Cann, P. Josse, P. Blanchard, C. Cabanetos and G. C. Welch, ACS Sustainable Chem. Eng. 2016, 4, 3504-3517.

[13] a) C. Réthoré, N. Avarvari, E. Canadell, P. Auban-Senzier and M. Fourmigué, J. Am. Chem. Soc. 2005, 127, 5748-5749; b) F. Pop, P. AubanSenzier, A. Frąckowiak, K. Ptaszyński, I. Olejniczak, J. D. Wallis, E. Canadell and N. Avarvari, J. Am. Chem. Soc. 2013, 135, 17176-17186.

[14] a) G. Gottarelli, G. Proni, G. P. Spada, D. Fabbri, S. Gladiali and C. Rosini, J. Org. Chem. 1996, 61, 2013-2019; b) Y. Yang, R. C. da Costa, D.-M Smilgies, A. J. Campbell and M. J. Fuchter, Adv. Mater. 2013, 25, 2624-2628 c) Y. Kim, M. Frigoli, N. Vanthuyne and N. Tamaoki, Chem. Commun. 2017, 53, 200-203. 
Unprecedented enantiopurity impact on OPV performance was observed with racemic and enantiomerically pure naphthalimide end-capped helicenes as non-fullerene molecular electron acceptors. Blended with P3HT donor polymer, a 5-fold increase of the cells efficiency was recorded going from the racemic to the enantiomerically pure electron acceptor, highlighting the key role of the enantiopurity of the $\pi$ conjugated backbone on the selfassembly, charge transport and therefore the overall photovoltaic properties.

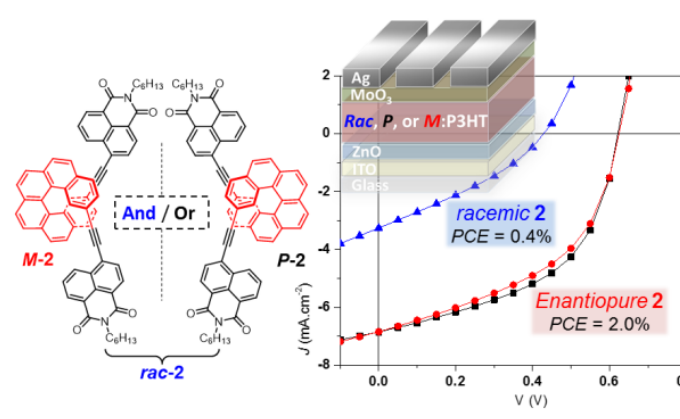

P. Josse, L. Favereau, ${ }^{*}$ C. Shen, S. DabosSeignon, P. Blanchard, ${ }^{\star}$ C. Cabanetos, ${ }^{*}$ and J. Crassous*

Enantiopure vs. Racemic Naphthalimide End-Capped Helicenic Non-Fullerene Electron Acceptors: Impact on Organic Photovoltaics Performance 
